1989

\title{
Mixed Convection in Vertical Internal Flow of a Micropolar Fluid
}

\author{
Rama Subba Reddy Gorla \\ Cleveland State University \\ Bahman Ghorashi \\ Cleveland State University \\ Prapat Wangskarn \\ Elilovelthis thandatadditional works at: https://engagedscholarship.csuohio.edu/encbe_facpub \\ Dart of the Complex Fluids Commons
}

How does access to this work benefit you? Let us know!

\section{Publisher's Statement}

NOTICE: this is the author's version of a work that was accepted for publication in International Journal of Engineering Science. Changes resulting from the publishing process, such as peer review, editing, corrections, structural formatting, and other quality control mechanisms may not be reflected in this document. Changes may have been made to this work since it was submitted for publication. A definitive version was subsequently published in International Journal of Engineering Science, 27, 12, (1989) DOI 10.1016/0020-7225(89)90148-1

\section{Original Citation}

ReddY Gorla, R., Ghorashi, B., , \& Wangskarn, P. (1989). Mixed convection in vertical internal flow of a micropolar fluid. International Journal of Engineering Science, 27(12), 1553-1561. doi:10.1016/ 0020-7225(89)90148-1

\section{Repository Citation}

Gorla, Rama Subba Reddy; Ghorashi, Bahman; and Wangskarn, Prapat, "Mixed Convection in Vertical Internal Flow of a Micropolar Fluid" (1989). Chemical \& Biomedical Engineering Faculty Publications. 53.

https://engagedscholarship.csuohio.edu/encbe_facpub/53

This Article is brought to you for free and open access by the Chemical \& Biomedical Engineering Department at EngagedScholarship@CSU. It has been accepted for inclusion in Chemical \& Biomedical Engineering Faculty Publications by an authorized administrator of EngagedScholarship@CSU. For more information, please contact library.es@csuohio.edu. 


\title{
MIXED CONVECTION IN VERTICAL INTERNAL FLOW OF A MICROPOLAR FLUID
}

\author{
RAMA SUBBA REDDY GORLA ${ }^{1}$, BAHMAN GHORASHI ${ }^{2}$ and \\ PRAPAT WANGSKARN ${ }^{1}$ \\ ${ }^{1}$ Department of Mechanical Engineering, Cleveland State University, Cleveland, OH 44115, U.S.A. \\ ${ }^{2}$ Department of Chemical Engineering, Cleveland State University, Cleveland, OH 44115, U.S.A.
}

\begin{abstract}
The theory of micropolar fluids due to Eringen is used to formulate a set of equations for the flow and heat transfer characteristics of the combined convection micropolar flow in vertical channels. It is found that the microstructure and substructure parameters have significant effects on the flow and thermal fields. By making the Newtonian solvent more and more micropolar, it is possible to obtain drag reduction as well as reduced heat transfer characteristics.
\end{abstract}

\section{INTRODUCTION}

There exist several approaches to study the mechanics of fluids with a substructure. Ericksen $[1,2]$ derived field equations which account for the presence of substructures in the fluid. It has been experimentally demonstrated by Hoyt and Fabula [3] and Vogel and Patterson [4] that fluids containing small amounts of polymeric additives display a reduction in skin friction.

Eringen [5] formulated the theory of micropolar fluids which display the effects of local rotary inertia and couple stresses. This theory can be used to explain the flow of colloidal fluids, liquid crystals, animal blood, etc. Eringen [6] extended the micropolar fluid theory and developed the theory of thermomicropolar fluids. A review of the study of micropolar fluid mechanics was provided by Ariman et al. [7].

Kanatani [8] presented a principle of converting a system of grid framework to an equivalent continuum model. A micropolar continuum was defined in the form of higher order extension. In order to supplement defects of previous theories, a complex-valued micropolar continuum model was constructed for grid frameworks vibrating with an arbitrary frequency by means of variational principles. The flow of granular materials at high deformation rates and low stress levels was studied by Kanatani [9] using a micropolar continuum theory. The constitutive equations were obtained by statistical inference. The material was assumed to consist of cohesionless rigid spheres of uniform size and the same mass. Two different regimes of flows, namely, slow flows and fast flows were analyzed. It was shown that the material exhibits the normal stress effects.

Brenner [10] has shown theoretically that the steady rotation of a container filled with a spatially uniform suspension of identical dipolar spherical particles in a Newtonian fluid would give rise to an antisymmetric stress state on the length scale of the suspension. He observed that an external torque must be continuously exerted on the container to maintain the steady rotation. The result was interpreted within the framework of micropolar fluid theory. For the case of concentrated suspensions of spheres whose centers are arrayed in a cubic lattice, expressions were obtained for all the parameters to characterize the phenomena. Brenner demonstrated that the swirling motion is a manifestation of the existence of a suspension-scale translational-slip velocity at the container walls.

Mixed convection flows in vertical channels and ducts find applications in nuclear reactors, heat exchangers and electronic equipment. Perhaps the most important question is the effect of buoyancy on forced convection transport rates. The buoyancy forces may aid or oppose the forced flow causing an increase or decrease in the heat transfer rates.

In the present paper, we have analyzed the fully developed laminar mixed convection flow of a micropolar fluid between two vertical parallel plates maintained at different values of uniform temperature. The set of coupled non-linear differential equations governing the flow, micro-rotation and temperature fields were solved by an iterative computational procedure. It is observed that the micropolar fluids display a reduction in wall shear stress as well as surface heat transfer rates. A discussion is provided for the effects of the dimensionless parameters $R$ 
(microstructure parameter) and $A$ (substructure parameter) on the details of flow and temperature fields.

\section{PROBLEM DESCRIPTION AND GOVERNING EQUATIONS}

Let us consider two infinite vertical parallel plates which are parallel to the direction of the gravitational body force. The $x$-axis is the axial direction and is located along the centerline of the channel. The $y$-direction is in the normal direction to the walls. The walls are kept at a distance $2 L$ apart and maintained at uniform temperatures $T_{1}$ and $T_{2}$. For a fully developed laminar flow with constant properties except for the density variation, which is included with the Boussinesq approximation, the governing equations are obtained by noting that the transverse velocity is zero. The normalized velocity and temperature distributions are taken as fully developed. The governing equations become

$$
\begin{gathered}
(\mu+k) \frac{\mathrm{d}^{2} u}{\mathrm{~d} y^{2}}+k \frac{\mathrm{d} N}{\mathrm{~d} y}-\frac{\mathrm{d} P}{\mathrm{~d} x}+\rho g \beta \theta=0 \\
\gamma \frac{\mathrm{d}^{2} N}{\mathrm{~d} y^{2}}-k \frac{\mathrm{d} u}{\mathrm{~d} y}-2 k N=0 \\
k_{f} \frac{\mathrm{d}^{2} \theta}{d y^{2}}-\left(\mu+\frac{k}{2}\right)\left(\frac{\mathrm{d} u}{\mathrm{~d} y}\right)^{2}+\frac{k}{2}\left(\frac{\mathrm{d} u}{\mathrm{~d} y}+2 N\right)^{2}+\gamma\left(\frac{\mathrm{d} N}{\mathrm{~d} y}\right)^{2}
\end{gathered}
$$

In the above equations, $u$ is the velocity component in axial direction, $N$ the component of micro-rotation, $\theta$ the temperature, $g$ the gravitational acceleration and $\beta$ the volumetric coefficient of thermal expansion. The boundary conditions are given by

$$
\begin{aligned}
& y=-L: u=0, N=N_{0}, \quad \theta=T_{1}-T_{e}=\theta_{1} \\
& y=L: u=0, N=N_{0}, \quad \theta=T_{2}-T_{e}=m \theta_{1}
\end{aligned}
$$

\section{ANALYSIS}

Proceeding with the analysis, we introduce the following dimensionless variables:

$$
\begin{aligned}
\eta & =\frac{y}{L} \\
f & =\frac{S u}{U_{0}} \\
\phi & =\frac{S \theta}{\theta_{1}} \\
\Omega & =\frac{L S}{U_{0}} \cdot N \\
U_{0} & =\frac{\rho g \beta \theta_{1} L^{2}}{\mu^{2}} \\
S & =\frac{\mu U_{0}^{2}}{k_{f} \theta_{1}} \\
R & =\frac{k}{\mu} \\
A & =\frac{\gamma}{k L^{2}}
\end{aligned}
$$


Upon substituting expressions in (5) into equations (1)-(4), we may write

$$
\begin{gathered}
(1+R) f^{\prime \prime}+R \Omega^{\prime}+\phi=\left(\frac{\mu U_{0}^{2}}{k_{f} \rho g \beta} \frac{\mathrm{d} P}{\mathrm{~d} x}\right) \\
A \Omega^{\prime \prime}-f^{\prime}-2 \Omega=0 \\
\phi^{\prime \prime}+\left(1+\frac{R}{2}\right)\left(f^{\prime}\right)^{2}+\frac{R}{2}\left(f^{\prime}+2 \Omega\right)^{2}+R A\left(\Omega^{\prime}\right)^{2}=0
\end{gathered}
$$

The normalized boundary conditions are given by

$$
\begin{array}{lrr}
\eta=-1: f=0, & \Omega=\Omega_{0}, & \phi=S \\
\eta=1: f=0, & \Omega=\Omega_{0}, & \phi=m S
\end{array}
$$

Equations (6)-(8) have been solved numerically on the computer by varying the microrotation parameters, $R$ and $A$ and the pressure gradient parameter

$$
\Delta P=\frac{\mu U_{0}^{2}}{k_{f} \rho g \beta} \frac{\mathrm{d} P}{\mathrm{~d} x}
$$

The case with

$$
\frac{\mathrm{d} P}{\mathrm{~d} x}=0
$$

corresponds to the free convection problem.

The dimensionless parameter, $S$ denotes the temperature level of the wall. An increase in the value of $S$ results in an increase of the fluid bulk temperature which in turn increases the mass flow rate. As the value of the pressure gradient parameter increases, the mass flow rate and the bulk temperature increase. The wall friction factor and the wall heat transfer rate (Nusselt number) get augmented with increasing pressure gradient in the streamwise direction. These details may be observed from the results presented in Appendices $\mathrm{A}$ and $\mathrm{B}$. The effect of the micropolar parameters $R$ and $A$ on the flow and thermal fields is observed to be significant. Increasing values of $R$ and $A$ result in reduction in wall shear stress and surface heat transfer rate. Figures 1 and 2 display typical velocity and temperature profiles. As the streamwise pressure gradient increases, we may observe that maximum velocity and maximum temperature in the channel increase.

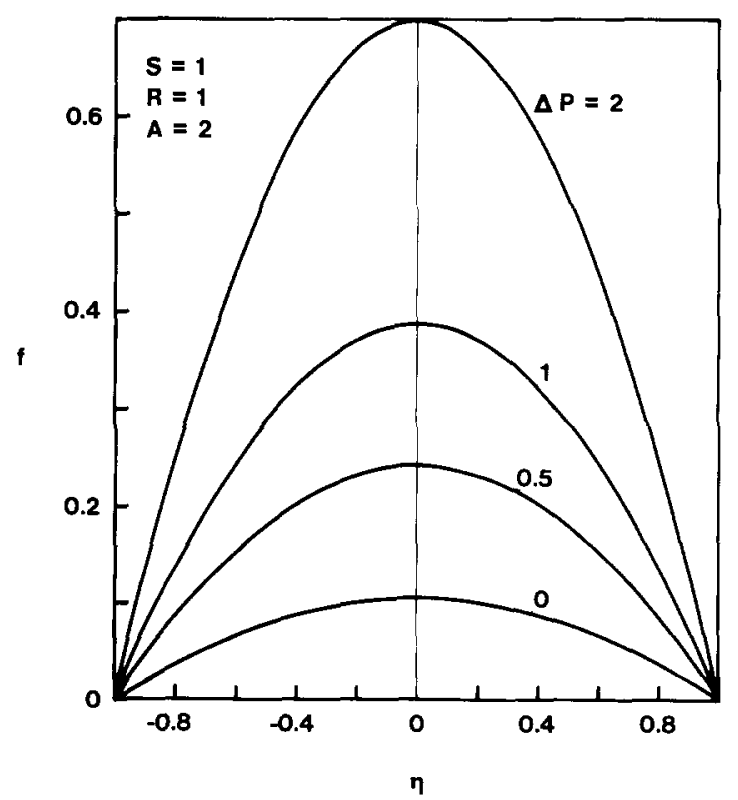

Fig. 1. Velocity distribution. 


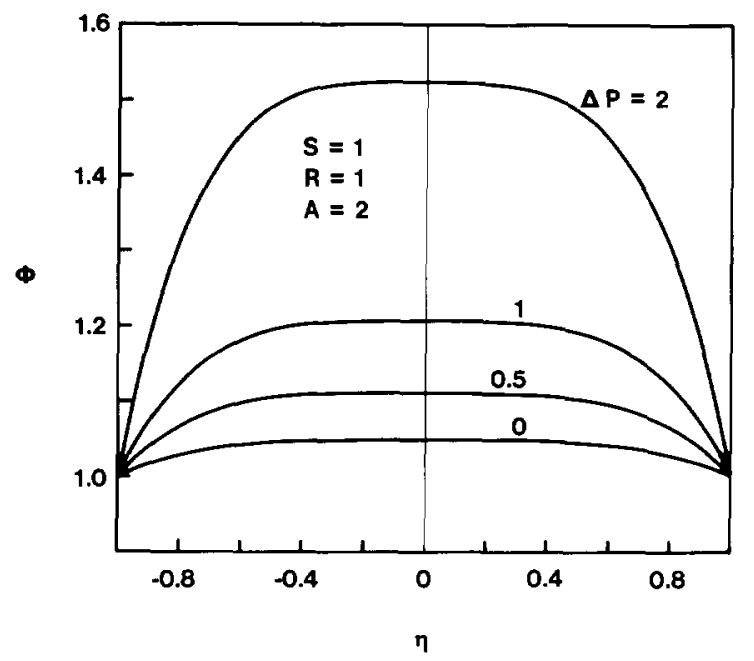

Fig. 2. Temperature distribution.

It is well known that turbulent flows exhibit internal structure in the form of eddies. This suggests that it may be possible to use theories of fluids with microstructure, such as Eringen's theory of simple microfluid [12], to model turbulent flow. In such an application the macrorotation of the model would correspond to the mean motion of the turbulent flow and the micro-inertia coefficients would correspond to the characteristic dimensions of the eddies. In [13, 14] Kirwan and Newman have found that both the micropolar fluid and simple microfluid models are capable of predicting turbulence-like velocity profiles in plane poiseuille and couette flows.

The problem of boundary conditions for structured fluids deserves some comment. Eringen [5], Condiff and Dahler [15] and Kirwan and Newman [13] discussed the case of rigid structures. Eringen [5] suggested that no spin boundary condition as being equivalent to a no slip condition for structures. Condiff and Dahler [15] proposed the no spin condition as well as one in which the skew symmetric component of the shear stresses vanished at rigid boundaries. Kirwan and Newman [13] argued that the reasoning leading to the restriction to these two conditions is not cogent. In the case of deformable structures, the question of restricting boundary conditions to those that are physically relevant is even more difficult. Thus Kirwan and Newman [14] selected the boundary values of the gyration as arbitrary, with some restrictions imposed, in the case of deformable structures. The general boundary conditions for the micro-rotation vector may have important applications. It has been demonstrated by Dahler and Scriven [16] that skew symmetric viscous stress arises quite naturally from considerations of molecular particle forces. It is quite possible that the boundaries are precisely the place where these effects are especially important. Fluids with rigid structures may have applications to fluids with polymeric additives. Fluids with deformable structures may model fluids with fluid inclusions such as a mixture of oil and water.

Kirwan [17] investigated the effect of different boundary conditions for micropolar fluids. For steady channel flow, it was shown that the boundary condition of micro-rotation rate being equal to minus one half of vorticity can reproduce the Navier Stokes results. A general linear relation between microrotation rate and vorticity at rigid boundaries was analyzed and several special cases were examined. Implications for more general flows were discussed by Kirwan.

Peddieson [18] considered the nonvanishing rotation boundary condition for the micropolar boundary layer flow at the stagnation point on a stationary wall. Gorla [19] investigated the steady boundary layer flow of a micropolar fluid at a two-dimensional stagnation point on a moving wall. He demonstrated that the micropolar fluid flow model is capable of predicting results which exhibit some of the flow characteristics found in turbulent boundary layers.

Appendix $C$ indicates wall shear stress values with the wall microrotation parameter changed from -3 to 3 . It is observed that as $\left|\Omega_{0}\right|$ increases, both the wall shear stress and the wall heat transfer rate increase. Figures 3 and 4 indicate that as the value of $\left|\Omega_{0}\right|$ increases, the velocity 


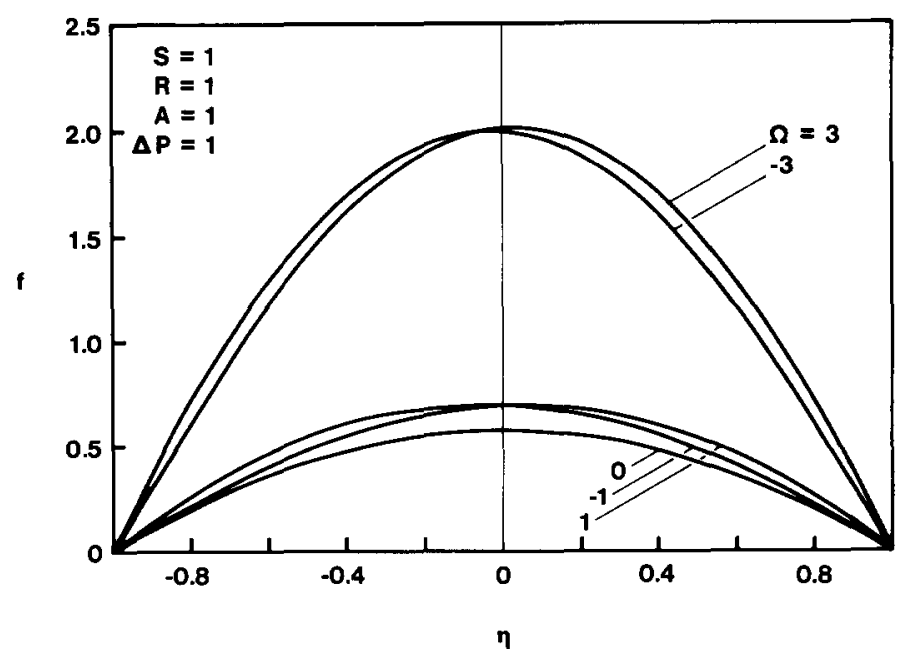

Fig. 3. Effect of surface value for the microrotation on the velocity distribution.

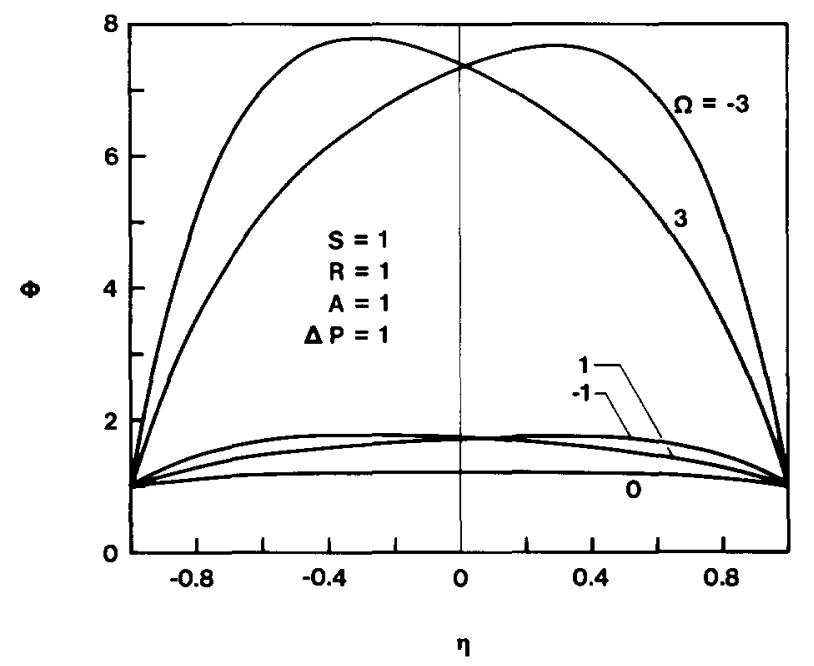

Fig. 4. Effect of surface value for the microrotation on the temperature distribution.

and temperature profiles become box type and thus the boundary condition for $\Omega_{0}$ plays an important role in simulating turbulent flows.

\section{CONCLUDING REMARKS}

The flow and heat transfer characteristics of the mixed convection flow of a micropolar fluid are studied in this paper. The effects of the microstructure parameter, $R$ and the substructure parameter $A$ on the flow and heat transfer are discussed. Micropolar fluids display drag reduction and heat transfer rate reduction. By varying the non-vanishing surface value for the microrotation vector, it is observed that it is possible to simulate turbulent type flows by means of the micropolar flow theory. Increasing values of surface microrotation vector result in enhancement in wall shear stress and surface heat transfer rate. As the pressure gradient parameter increases, the mass flow rate and the bulk temperature increase which in turn augment the friction factor and Nusselt number. Increasing values of the dimensionless microstructure parameter and substructure parameters result in the reduction of drag and heat transfer rates. 


\section{REFERENCES}

[1] J. L. ERICKSEN, Arch. Rat. Mech. Anal, 4, 132 (1960).

[2] J. L. ERICKSEN, Kolloidzeitshrift 173, 117 (1960).

[3] J. W. HOYT and A. G. FABULA, U.S. Naval Ordinance Test Station Report (1964)

[4] W. M. VOGEL and A. M. PATTERSON, Pacific Naval Laboratory of the Defense Research Board of Canada, Report 64-2 (1964).

[5] A. C. ERINGEN, J. Math. Mech. 16, 1 (1966).

[6] A. C. ERINGEN, J. Math. Anal. Appl. 38, 480 (1972).

[7] T. ARIMAN, M. A. TURK and N. D. SYLVESTER, Int. J. Engng Sci. 12, 273 (1974)

[8] K. KANATANI, Int. J. Engng Sci. 17, 409 (1979).

[9] K. KANATANI, Int. J. Engng Sci. 17, 419 (1979).

[10] H. BRENNER, Int. J. Engng Sci. 22, 645 (1984).

[11] M. BALARAM and V. U. K. SASTRY, Int. J. Heat Mass Transfer 16, 437 (1973).

[12] A. C. ERINGEN, Int. J. Engng Sci. 2, 205 (1964).

13] A. D. KIRWAN and N. NEWMAN, Int. I. Engng Sci. 7, 883 (1969).

[14] A. D. KIRWAN and N. NEWMAN, Int. J. Engng Sci. 7, 1067 (1969).

[15] D. W. CONDIFF and J. S. DAHLER, Phys. Fluids 7, 842 (1964).

(16] J. S. DAHLER and L. E. SCRIVEN, Proc. R. Soc. A275, 504 (1963).

[17] A. D. KIRWAN, Int. J. Engng Sci. 24, 1237 (1986).

[18] J. PEDDIESON, Int. J. Engng Sci. 19, 23 (1972).

[19] R. S. R. GORLA, Int. J. Engng Sci. 21, 25 (1983).

(Received 2 May 1989)

\section{NOMENCLATURE}

$A$

dimensionless micro-rotation parameter

$$
\left(\frac{\gamma}{k L^{2}}\right)
$$

$f \quad$ dimensionless velocity function

$g \quad$ acceleration due to gravity

$k_{f} \quad$ thermal conductivity one-half distance between the plates wall temperature parameter angular velocity

Nusselt number

pressure

dimensionless pressure gradient

$\left(\frac{\mu U_{0}^{2}}{k_{f} \rho g \beta} \frac{\mathrm{d} P}{\mathrm{~d} x}\right)$

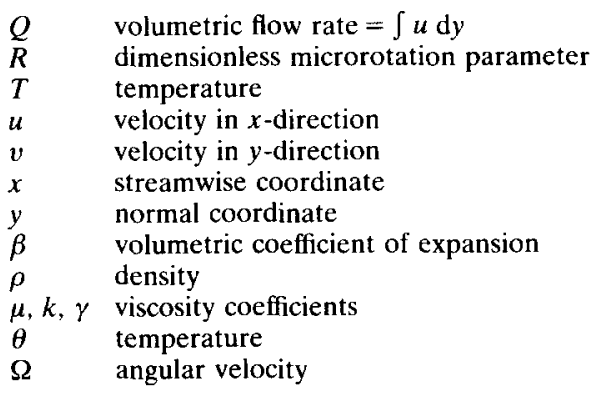

APPENDIX A

Values of Mass Flow Rate $Q$ and Nusselt Number Nu

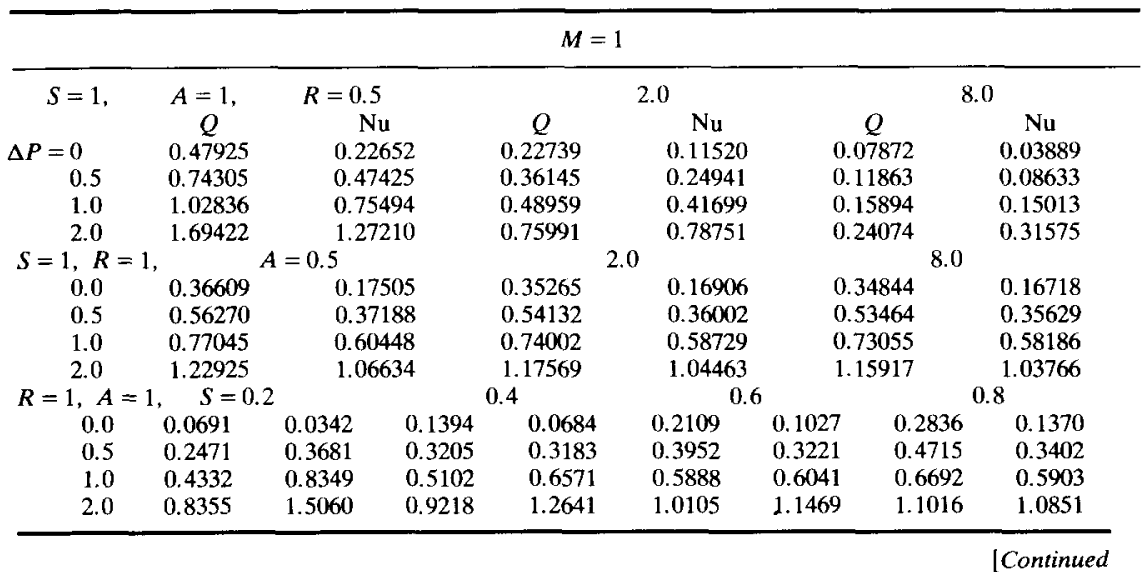




\begin{tabular}{|c|c|c|c|c|c|c|c|c|}
\hline \multicolumn{9}{|c|}{$M=2$} \\
\hline \multirow{2}{*}{$S=1, A=1$} & \multicolumn{3}{|c|}{$R=0.5$} & \multicolumn{2}{|c|}{2.0} & \multicolumn{3}{|c|}{8.0} \\
\hline & \multirow{3}{*}{$\frac{Q}{0.74287}$} & \multicolumn{2}{|c|}{$\mathrm{Nu}$} & \multirow{3}{*}{$\underset{0.36124}{Q}$} & \multirow{3}{*}{$\begin{array}{c}\mathrm{Nu} \\
0.16666 \\
0.70657\end{array}$} & \multicolumn{2}{|c|}{$Q$} & $\mathrm{Nu}$ \\
\hline \multirow[t]{2}{*}{$\Delta P=0.0$} & & \multirow{2}{*}{\multicolumn{2}{|c|}{$\begin{array}{l}0.12268 \\
0.92436\end{array}$}} & & & \multicolumn{2}{|c|}{0.11853} & 0.37731 \\
\hline & & & & & & & & 0.56471 \\
\hline 0.5 & 1.02813 & \multicolumn{2}{|c|}{0.47104} & \multirow{2}{*}{0.48936} & 0.04088 & \multicolumn{2}{|c|}{0.15884} & 0.29983 \\
\hline & & \multicolumn{2}{|c|}{1.25509} & & 0.87607 & \multirow{2}{*}{\multicolumn{2}{|c|}{0.19955}} & 0.62334 \\
\hline 1.0 & 1.34148 & \multicolumn{2}{|c|}{0.81006} & \multirow[t]{2}{*}{0.62198} & 0.26950 & & & 0.20449 \\
\hline & & \multicolumn{2}{|c|}{1.63805} & & 1.08213 & & & 0.69702 \\
\hline 2.0 & 2.10579 & \multirow{2}{*}{\multicolumn{2}{|c|}{$\begin{array}{l}1.36405 \\
2.44696\end{array}$}} & \multirow[t]{2}{*}{0.90301} & \multirow{2}{*}{$\begin{array}{l}0.72037 \\
1.51658\end{array}$} & \multirow{2}{*}{\multicolumn{2}{|c|}{0.28218}} & 0.02267 \\
\hline & & & & & & & & 0.88427 \\
\hline$S=1, R=1$, & $A=$ & 0 . & & 2.0 & 8.0 & & & \\
\hline 0.0 & 0.56245 & 0.00 & & 0.54109 & 0.02476 & & 0.11853 & 0.37731 \\
\hline & & 0.82 & & & 0.81043 & & & 0.56471 \\
\hline 0.5 & 0.77016 & 0.28 & & 0.73978 & 0.04088 & & . 15884 & 0.29983 \\
\hline & & 1.07 & & & 0.87607 & & & 0.62334 \\
\hline 1.0 & 0.99127 & 0.57 & & 0.95035 & 0.26950 & & 0.19955 & 0.20449 \\
\hline & & 1.37 & & & 1.08213 & & & 0.69702 \\
\hline 2.0 & 1.48753 & $1.0 \mathrm{~s}$ & & 1.41849 & 0.72037 & & 0.28218 & 0.02267 \\
\hline & & 2.04 & & & 1.56158 & & & 0.88427 \\
\hline$A=1, R=1$, & $S=$ & & & 0.4 & 0. & & & 8 \\
\hline$\Delta P=0.0$ & 0.1040 & 0.3909 & 0.2107 & 0.2949 & 0.3202 & 0.2009 & 0.4320 & 0.1088 \\
\hline & & 0.5563 & & 0.6192 & & 0.6831 & & 0.7482 \\
\hline 0.5 & 0.2835 & 0.0806 & 0.3951 & 0.0739 & 0.5060 & 0.1264 & 0.6285 & 0.1936 \\
\hline & & 0.9387 & & 0.9190 & & 0.9549 & & 1.0063 \\
\hline 1.0 & 0.4714 & 0.6522 & 0.5886 & 0.5007 & 0.7098 & 0.4865 & 0.8352 & 0.5141 \\
\hline & & 1.5208 & & 1.3333 & & 1.3048 & & 1.3228 \\
\hline 2.0 & 0.8783 & 1.4242 & 1.0102 & 1.1946 & 1.1479 & 1.1059 & 1.2922 & 1.0771 \\
\hline & & 2.6349 & & 2.2292 & & 2.0782 & & 2.0223 \\
\hline
\end{tabular}

\section{APPENDIX B}

Values of Shear Stress at the Wall $u^{\prime}(0)$

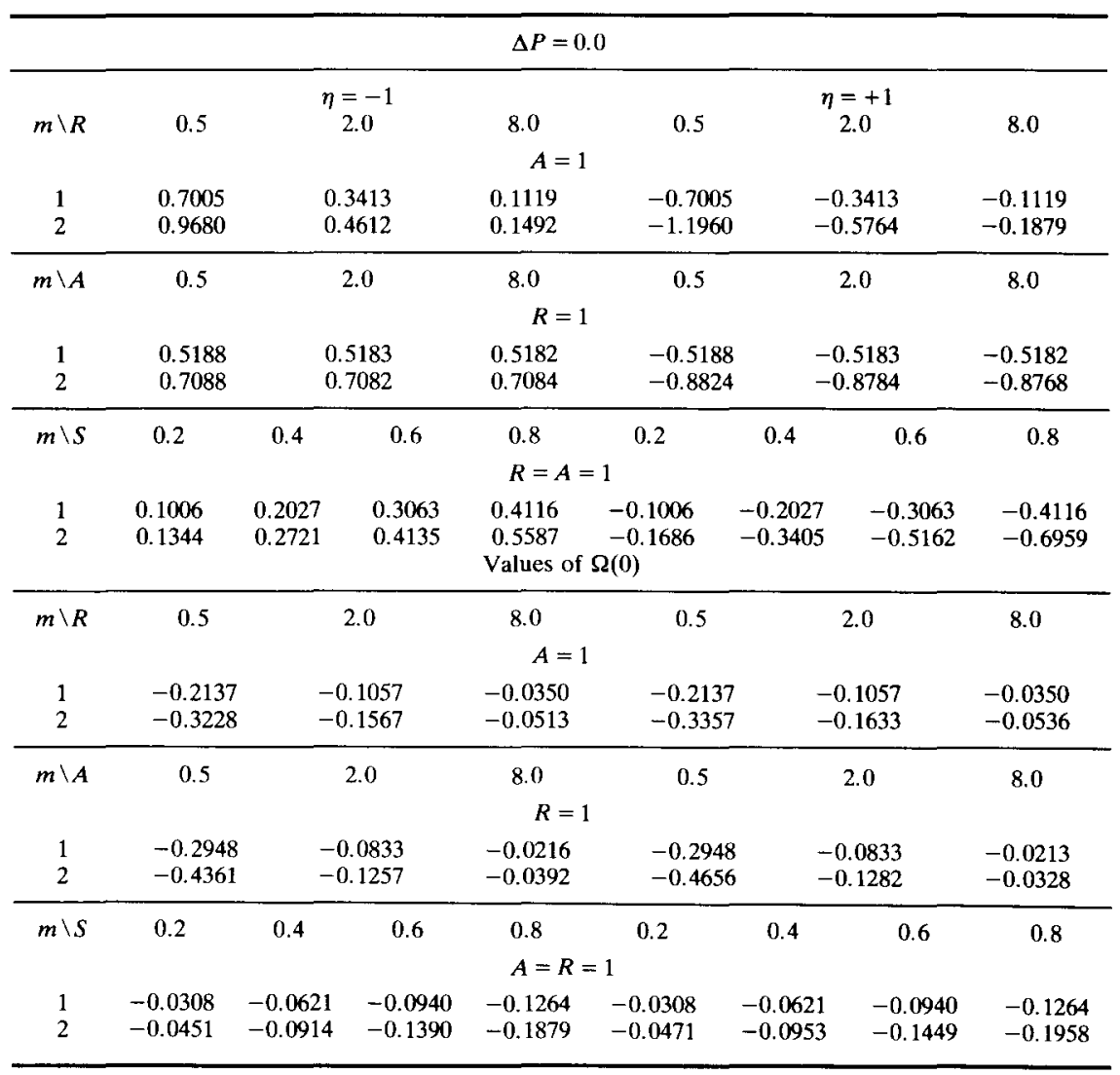


Appendix B continued]

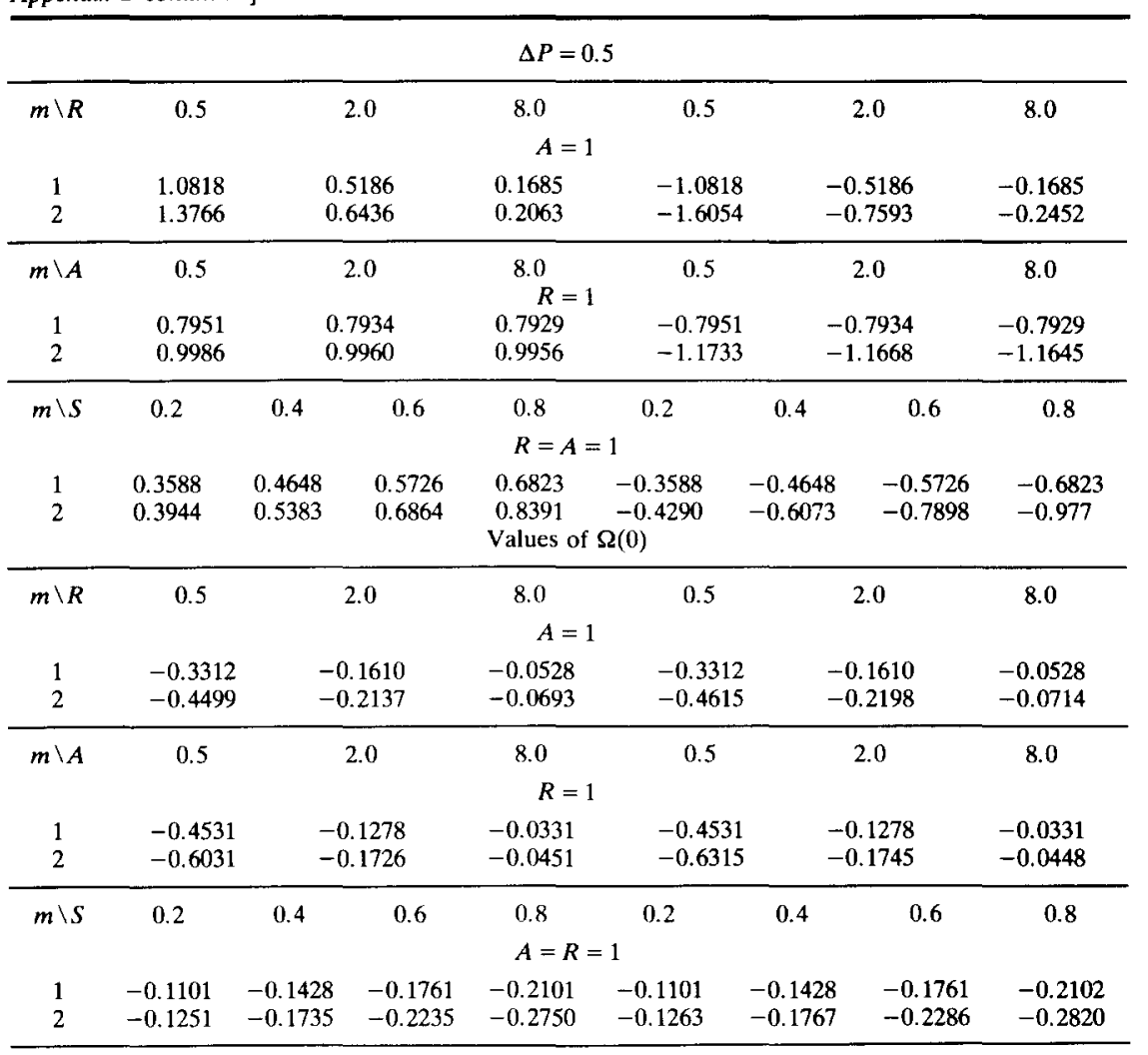

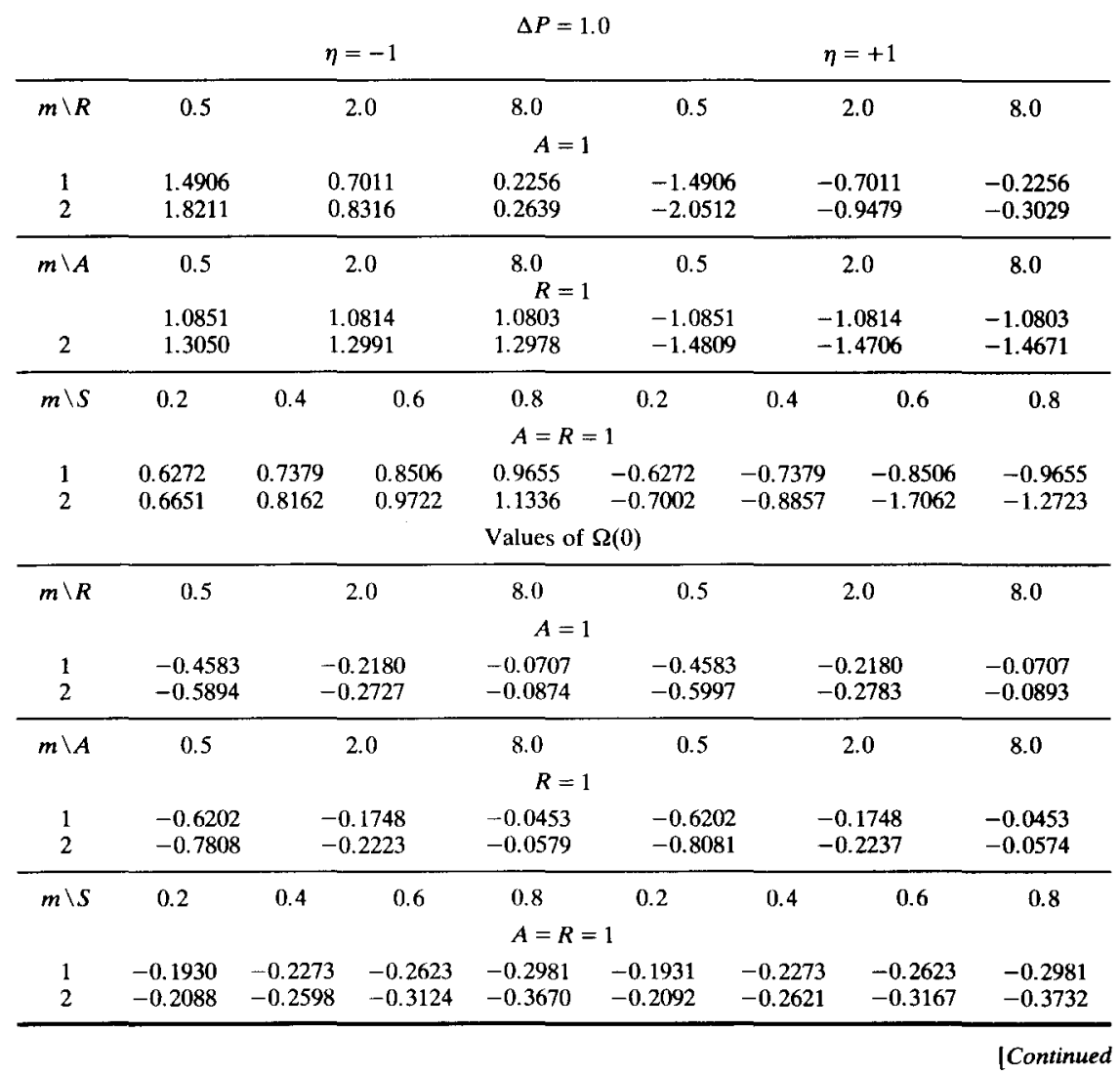


Appendix B continued]

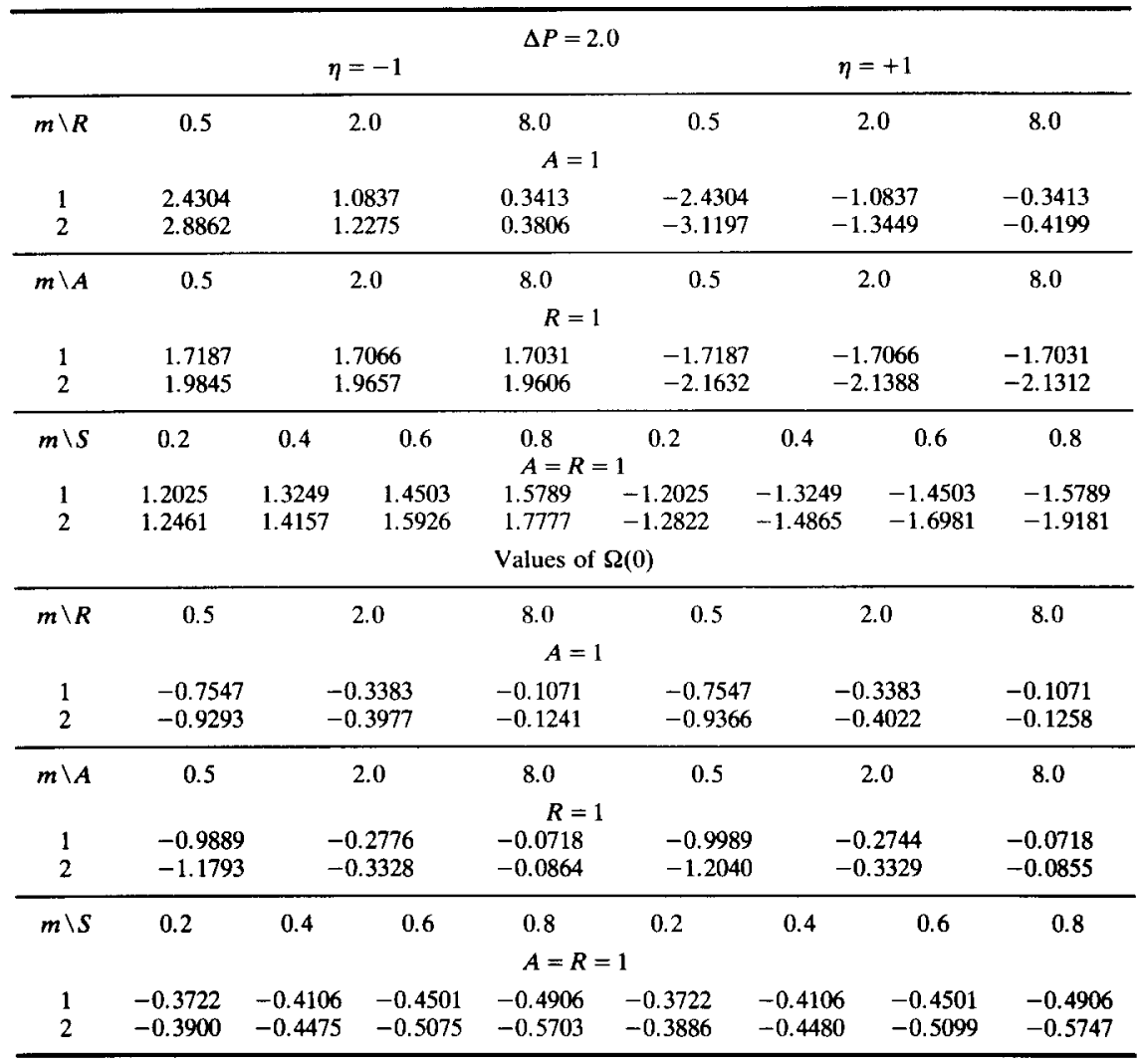

APPENDIX C

Effect of Wall Microrotation Parameter on Shear Stress, Mass Flow Rate and Nusselt Number

\begin{tabular}{|c|c|c|c|c|c|c|c|c|c|c|}
\hline \multicolumn{11}{|c|}{$u^{\prime}(0)$} \\
\hline \multicolumn{7}{|c|}{$\eta=1$} & \multicolumn{2}{|c|}{$\eta=-1$} & \multirow[b]{2}{*}{$\begin{array}{c}1 \\
-0.8653 \\
-1.4430\end{array}$} & \multirow[b]{2}{*}{$\begin{array}{c}3 \\
-2.8381 \\
-3.8086\end{array}$} \\
\hline $\begin{array}{r}\Omega(0)= \\
\Delta P=0 \\
1\end{array}$ & $\begin{array}{c}-3 \\
2.8263 \\
3.7787\end{array}$ & $\begin{array}{c}-1 \\
0.8664 \\
1.4425\end{array}$ & $\begin{array}{c}0 \\
0.5185 \\
1.0827\end{array}$ & $\begin{array}{c}1 \\
0.5056 \\
1.0991\end{array}$ & $\begin{array}{c}3 \\
1.9316 \\
2.9987 \\
\Omega^{\prime}(0)\end{array}$ & $\begin{array}{c}-3 \\
-1.9367 \\
-2.9888\end{array}$ & $\begin{array}{c}-1 \\
-0.5096 \\
-1.1034\end{array}$ & $\begin{array}{c}0 \\
-0.5185 \\
-1.0827\end{array}$ & & \\
\hline $\begin{array}{r}\Omega(0)= \\
\Delta P=0 \\
1\end{array}$ & $\begin{array}{c}-3 \\
2.9240 \\
2.6009\end{array}$ & $\begin{array}{c}-1 \\
1.0249 \\
0.8434\end{array}$ & $\begin{array}{c}0 \\
-0.1594 \\
-0.3347\end{array}$ & $\begin{array}{c}1 \\
-1.4627 \\
-1.6462\end{array}$ & $\begin{array}{c}3 \\
-4.5608 \\
-4.8996\end{array}$ & $\begin{array}{c}-3 \\
-4.5541 \\
-4.8837\end{array}$ & $\begin{array}{c}-1 \\
-1.4622 \\
-1.6437\end{array}$ & $\begin{array}{c}0 \\
-0.1594 \\
-0.3347\end{array}$ & $\begin{array}{c}1 \\
1.0283 \\
0.8482\end{array}$ & $\begin{array}{c}3 \\
2.9302 \\
2.6039\end{array}$ \\
\hline
\end{tabular}

\begin{tabular}{|c|c|c|c|}
\hline \multicolumn{4}{|c|}{$\Delta P=0$} \\
\hline & & \multicolumn{2}{|c|}{$\mathrm{Nu}$} \\
\hline & $Q$ & $\eta=-1$ & $\eta=1$ \\
\hline$\Omega(0)=-3$ & 1.8451 & 1.2430 & 2.0490 \\
\hline-1 & 0.4931 & 0.6760 & 1.0280 \\
\hline 0 & 0.3577 & 0.1713 & 0.1694 \\
\hline 1 & 0.4916 & 1.0354 & 0.6653 \\
\hline 3 & 1.8505 & 2.0615 & 1.2336 \\
\hline \multicolumn{4}{|c|}{$\Delta P=1$} \\
\hline & & \multicolumn{2}{|c|}{$\mathrm{Nu}$} \\
\hline & $Q$ & $\eta=-1$ & $\eta=1$ \\
\hline$\Omega(0)=-3$ & 2.5831 & 1.2554 & 2.1895 \\
\hline-1 & 0.9026 & 0.7935 & 1.3435 \\
\hline 0 & 0.7514 & 0.5937 & 0.5894 \\
\hline 1 & 0.9018 & 1.3530 & 0.7874 \\
\hline 3 & 2.6021 & 2.2028 & $1 \cdot 2467$ \\
\hline
\end{tabular}

Post-print standardized by MSL Academic Endeavors, the imprint of the Michael Schwartz Library at Cleveland State University, 2014 